\title{
Dossier
}

\section{MENTALMENTE TRANSITABLE}

Quirarte + ORNELAS

Artistas visuales

www.quirarteornelas.com

\begin{abstract}
1 tiempo en que se escribe este texto, México y el mundo se han visto afectados por una situación sanitaria que ha detenido prácticamente toda actividad de interacción humana. Una gran parte de la población se encuentra confinada en sus espacios personales en algo que se ha convertido en una prueba al temple, una invitación a la introspección y a la observación del espacio inmediato. En esta reflexión constante nos han surgido respuestas a preguntas que hemos formulado en nuestra obra de manera inherente a la producción. Y, por supuesto, más preguntas.
\end{abstract}


La creación de arte, desde nuestro flanco, siempre ha ido de lo particular a lo general, desde una perspectiva íntima directamente ligada con el quehacer artístico, partiendo de la experiencia personal: la cotidianeidad, la experimentación del material y de la forma, la apropiación de elementos que vienen desde lo local y que terminan conectando con la experiencia colectiva. Buscamos dejar nuestra obra en un punto en el que ésta presente en cuerpo y forma, de manera autónoma a un texto discursivo, la información necesaria para que el espectador tenga un entendimiento de la misma desde su experiencia personal.

Los años recientes de nuestra producción han tomado camino por diferentes medios en una necesidad por investigar los límites entre ellos y la manera en que pueden tenderse puentes para cruzar de uno a otro, contraponerlos, matizarlos, alargarlos, traerlos al frente del discurso, y ha sido en la geometría, a la que llegamos desde un largo camino de reconfiguración de elementos, en la que encontramos un amplio terreno para nuestra investigación.

A estos diversos medios se suma de manera indirecta la Arquitectura, a la cual nos acercamos de manera coincidental inicialmente en nuestras esculturas y que se volvió esencial en la configuración discursiva y visual de un buen número de nuestras piezas, en las que entablamos un diálogo con movimientos históricos como el Suprematismo, el Constructivismo y el Brutalismo. A través de la presencia de luz y sombra, de la configuración de los elementos y de la modificación de escala en la transición de las esculturas a sus diversas representaciones bidimensionales, esta investigación ha devenido en un tema que se ha vuelto fundamental en nuestra obra más reciente: la evocación de espacios mentalmente transitables.

En nuestro proceso de trabajo, la creación de los proyectos desde lo conceptual hasta lo formal es tan importante como nuestra propia percepción de los mismos a lo largo del tiempo. Esto nos permite una visión más objetiva de éstos, lo cual da pie a la generación de nuevos proyectos que siempre permanecen ligados a los anteriores, trabajando de manera cíclica y concatenada como lo hemos hecho a lo largo de 16 años de colaboración.

Este ejercicio de análisis genera preguntas con diversas respuestas en correspondencia al momento en el que se formulan, poniéndonos como espectadores ante nuestra propia obra. Hablando del momento presente, desde este confinamiento hasta hoy voluntario nos hemos encontrado con las preguntas: ¿cuál es el propósito del arte?, ¿por qué trabajamos con las manos?, ¿por qué pintamos? Una cosa queda 
clara: el arte es una herramienta para entendernos a nosotros mismos, al otro, el entorno y el momento; el arte le da sentido al ser humano.

Somos creadores pero sobre todo espectadores. A través del arte se puede ver la presencia del otro, la mano, la respiración, aquello que sucede del cerebro del artista a la obra. En esta distancia estamos solos pero el tiempo congelado en una pieza nos lleva a otros momentos, a otros espacios. Incluso en nuestra propia obra podemos percibir el yo -el nosotros- de otro tiempo y generar un diálogo, que casi siempre deviene en más preguntas. Es así que, entre tantas definiciones posibles, el arte es también un espacio mentalmente transitable.

Marzo 31, 2020. 


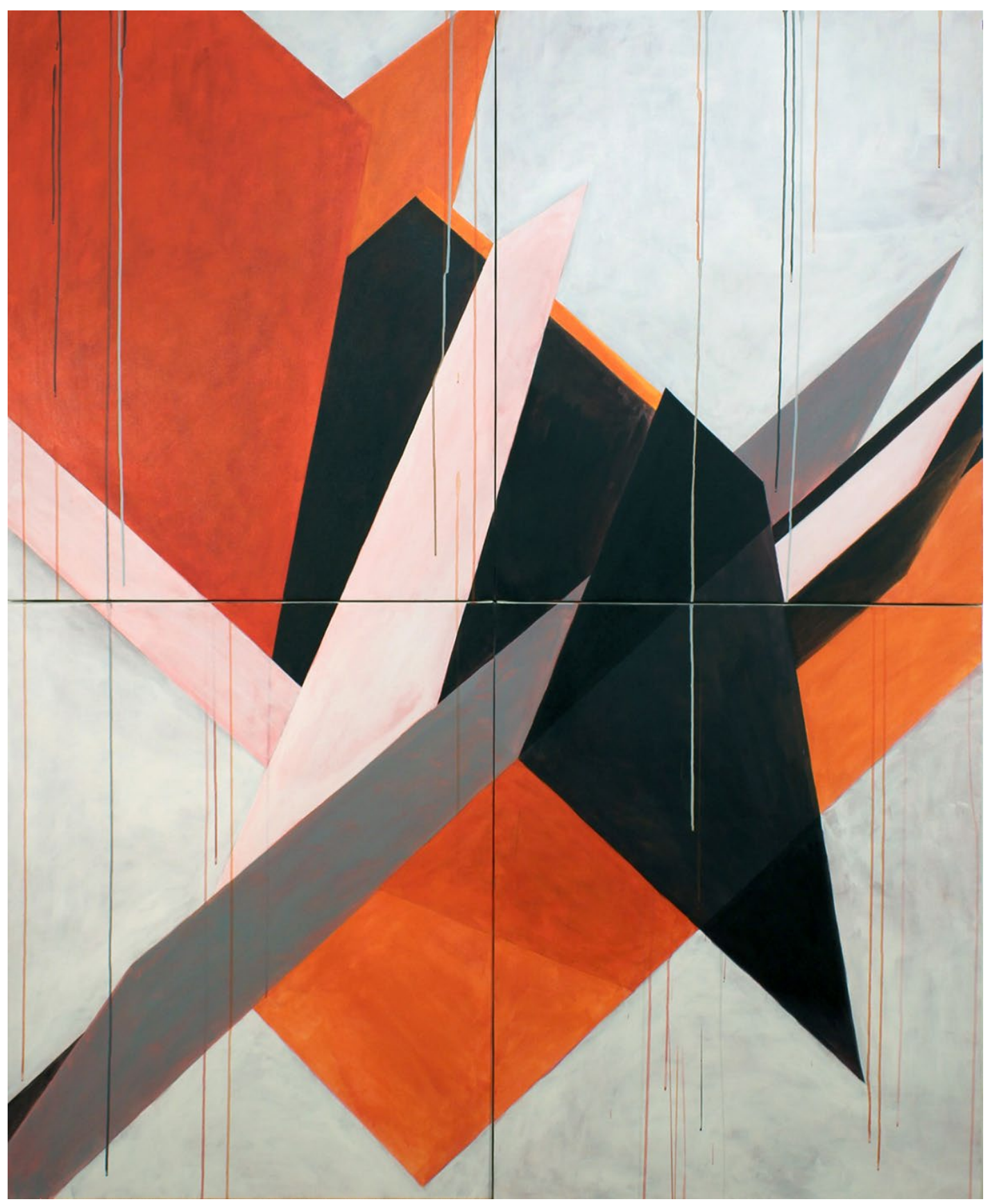




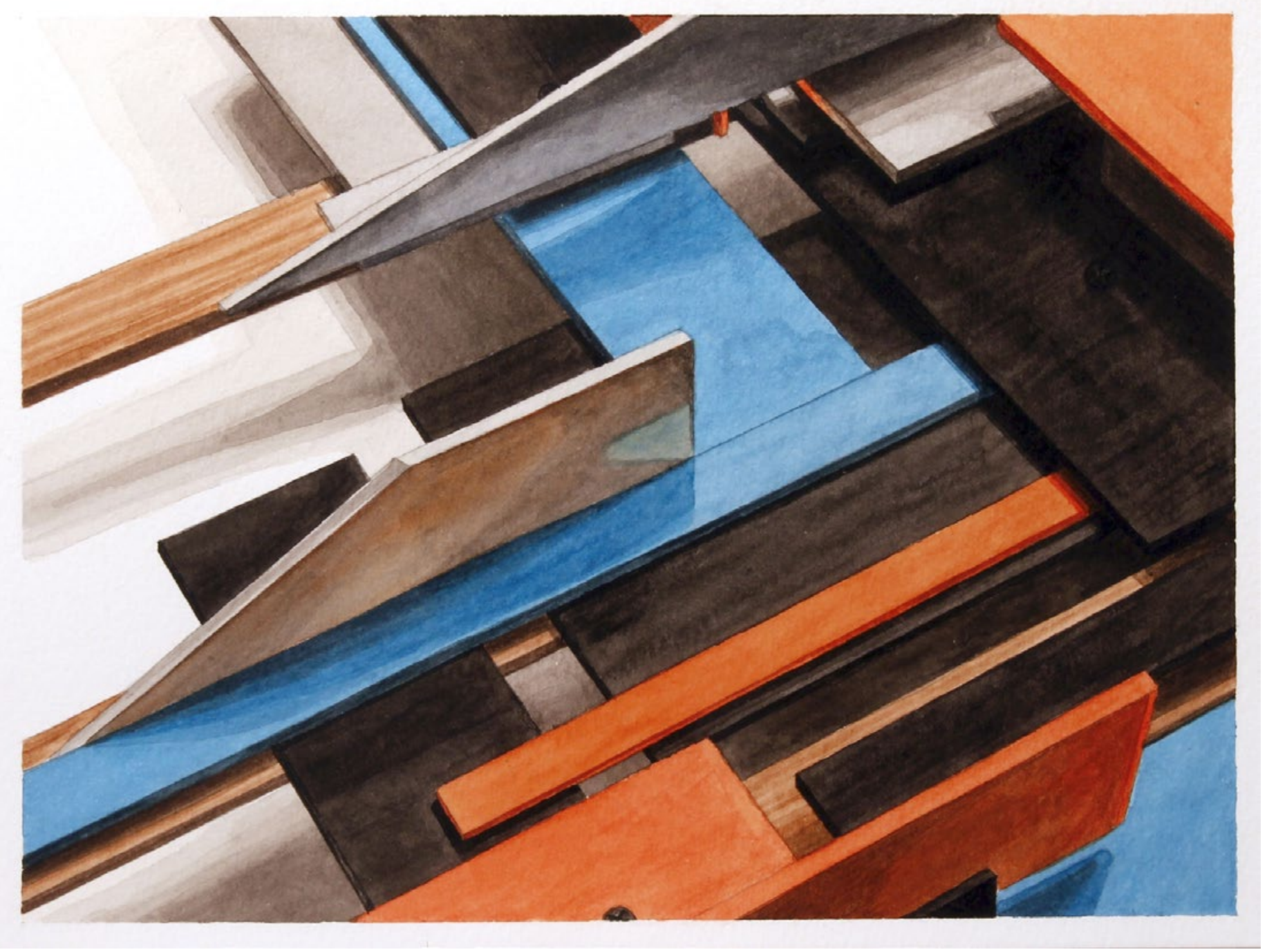




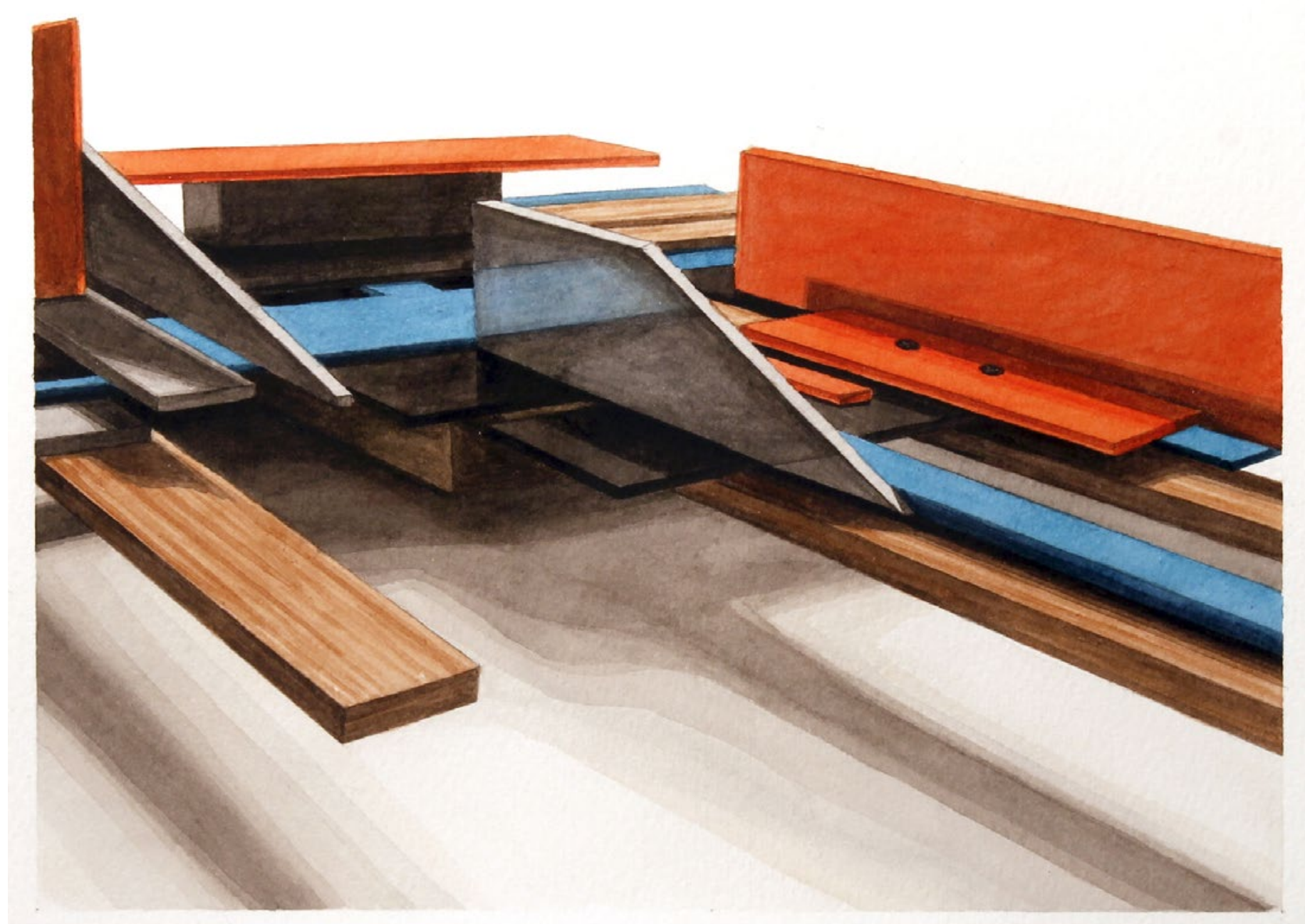









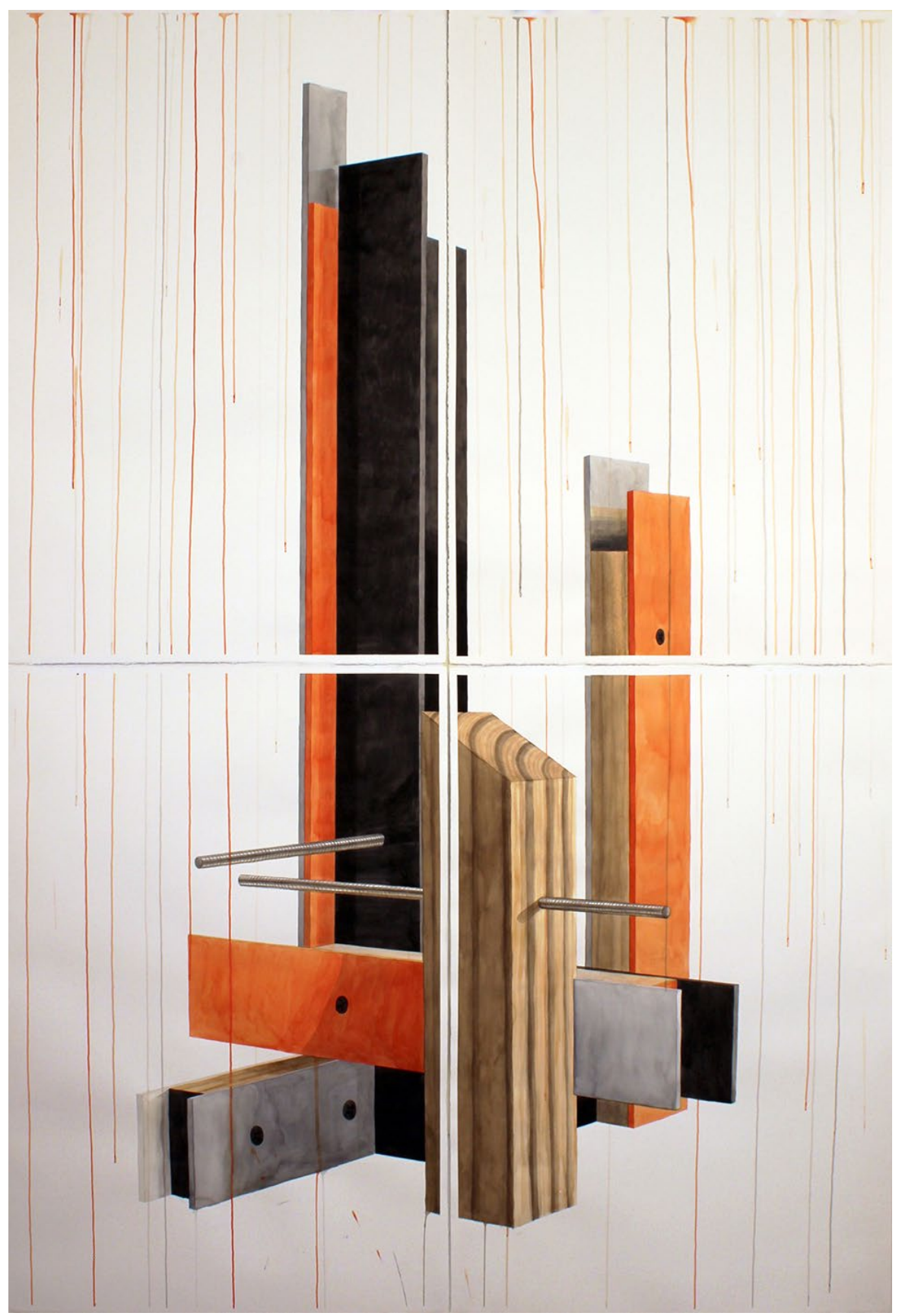




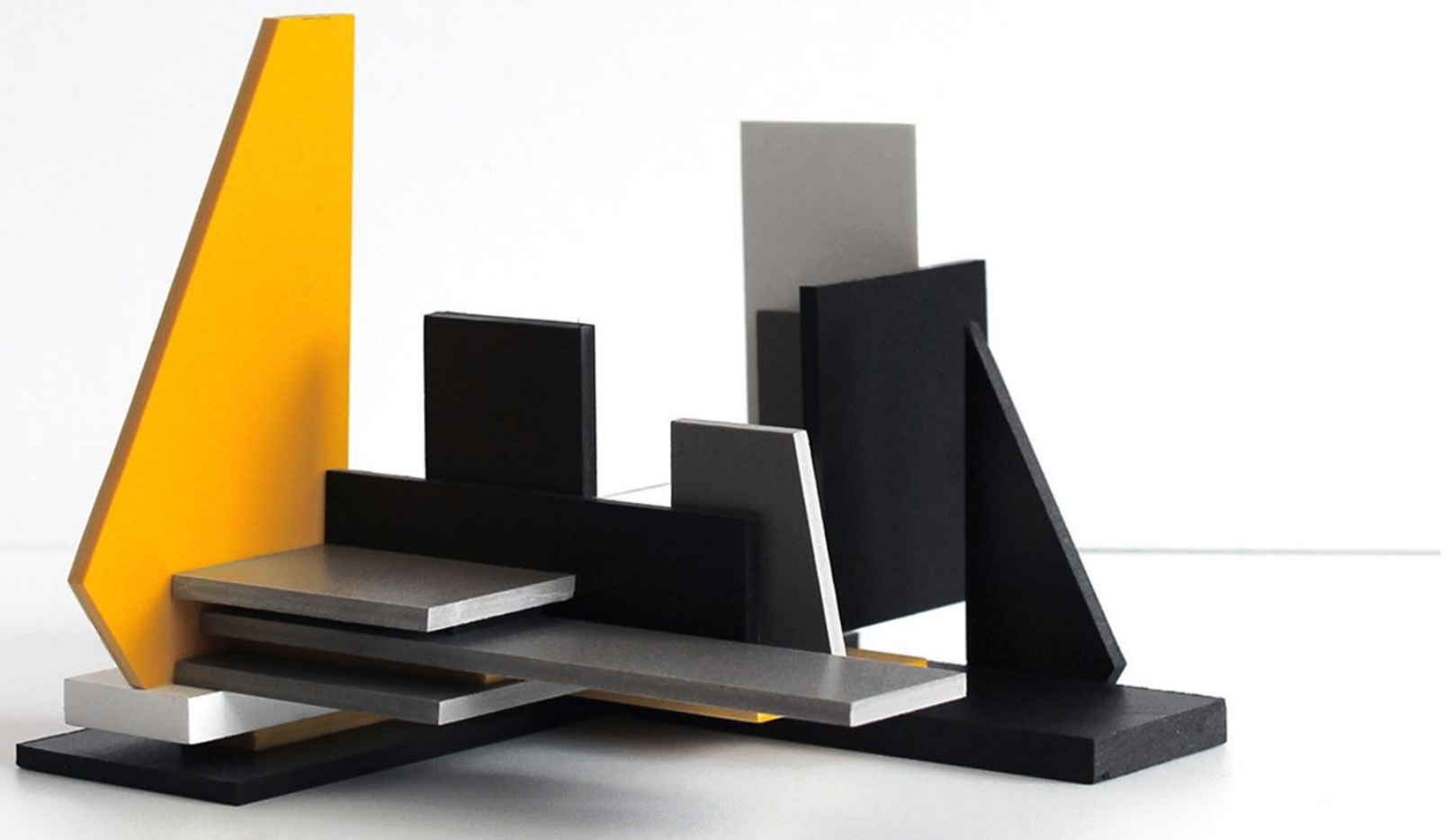




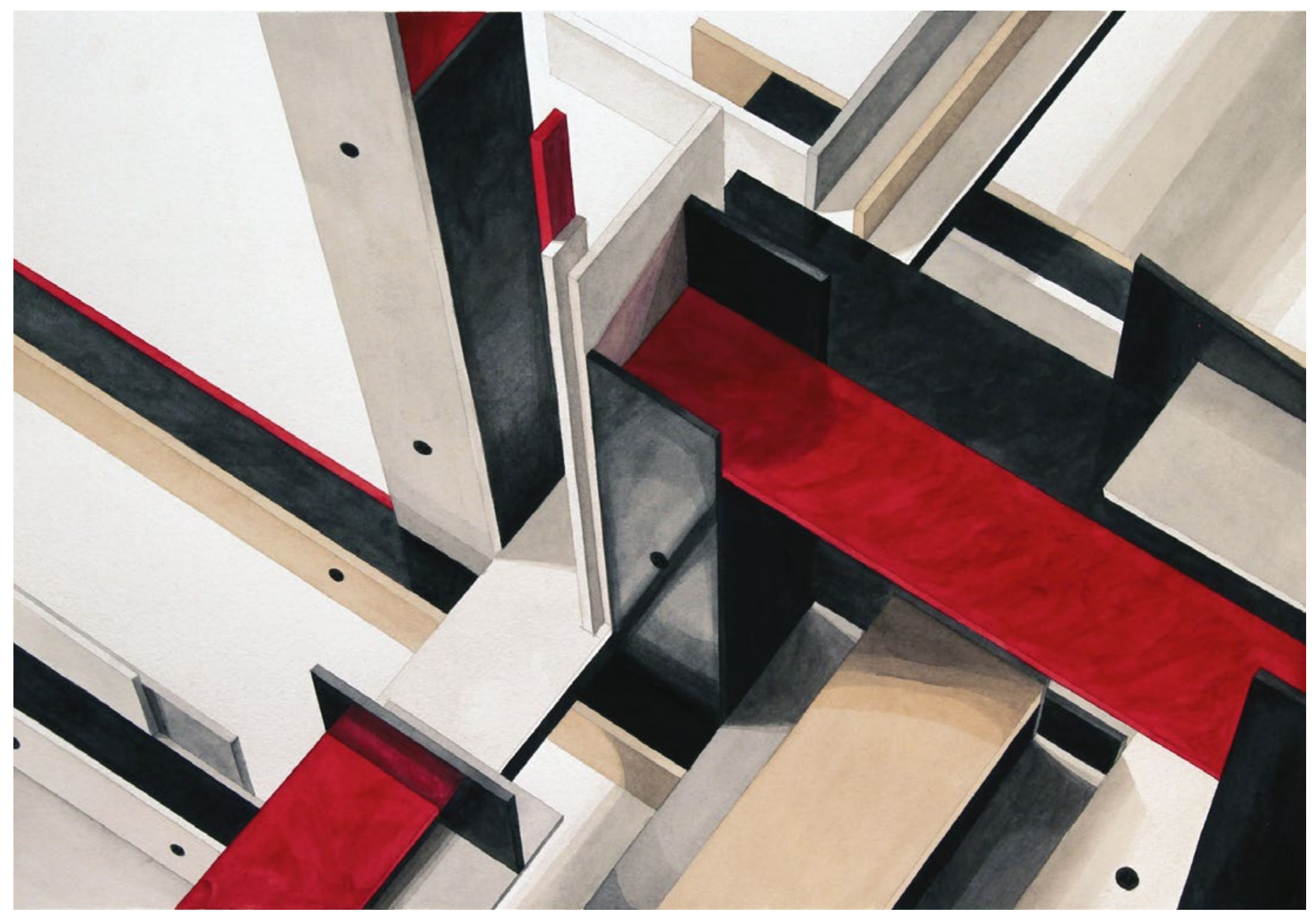









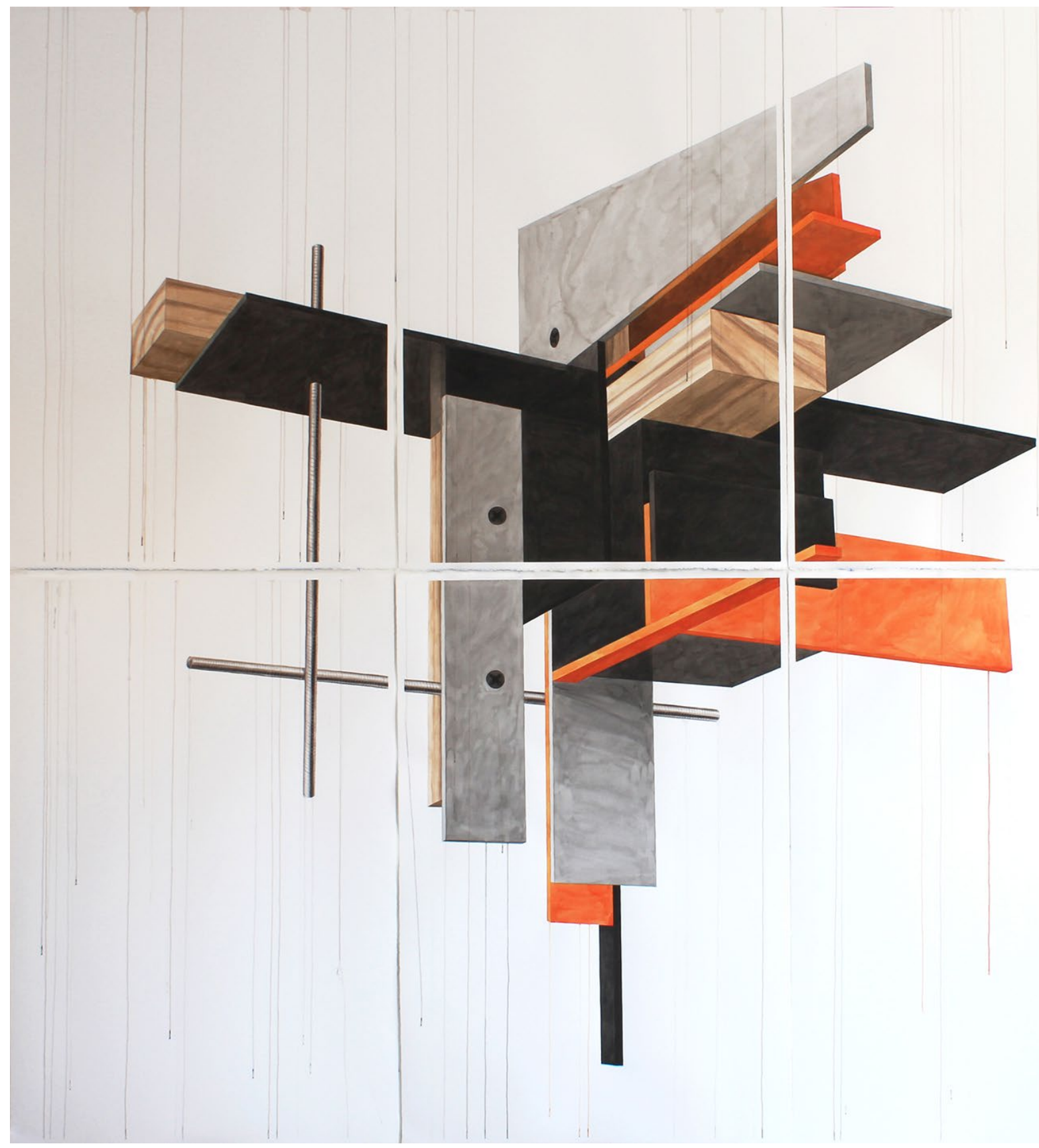




$$
1
$$




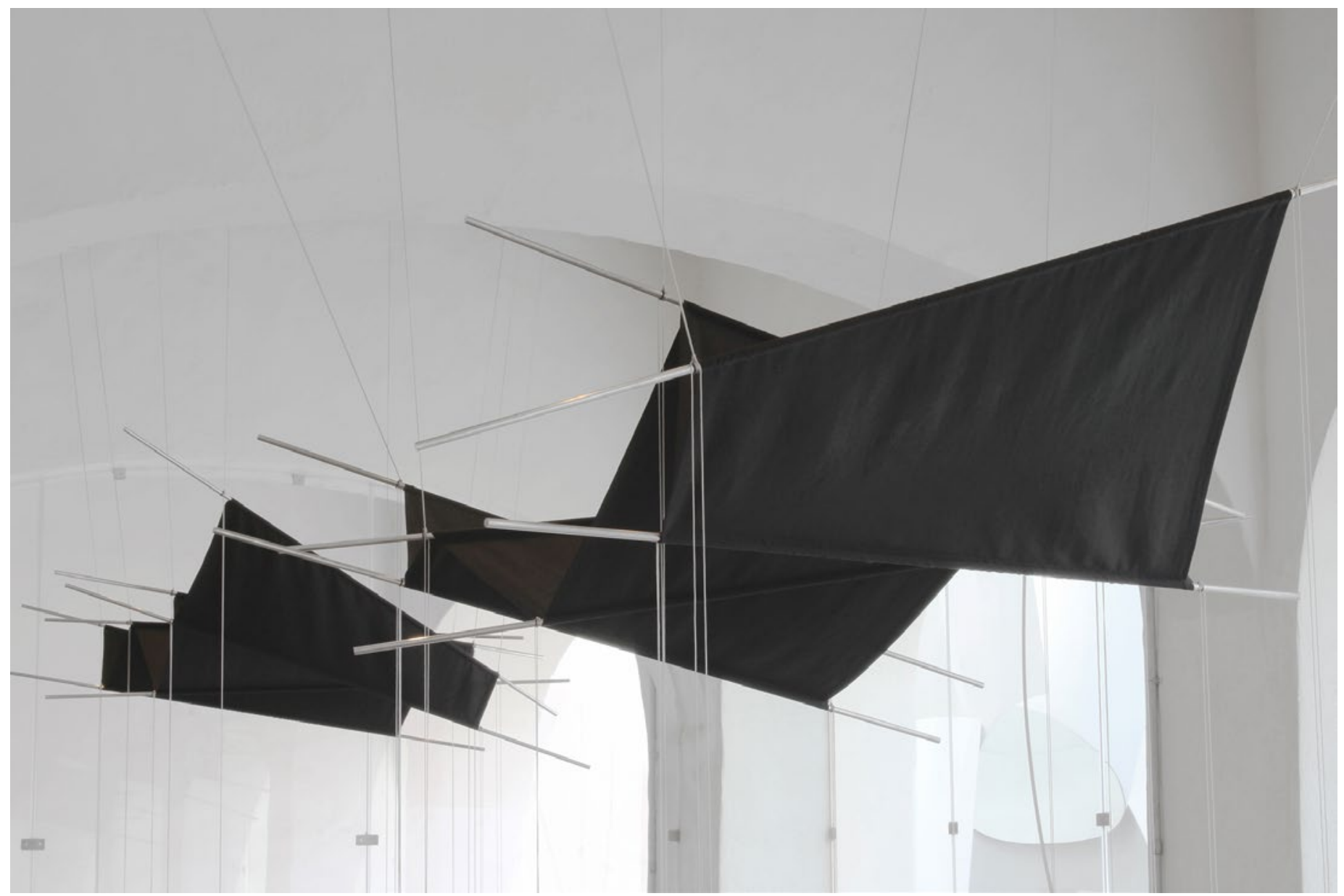




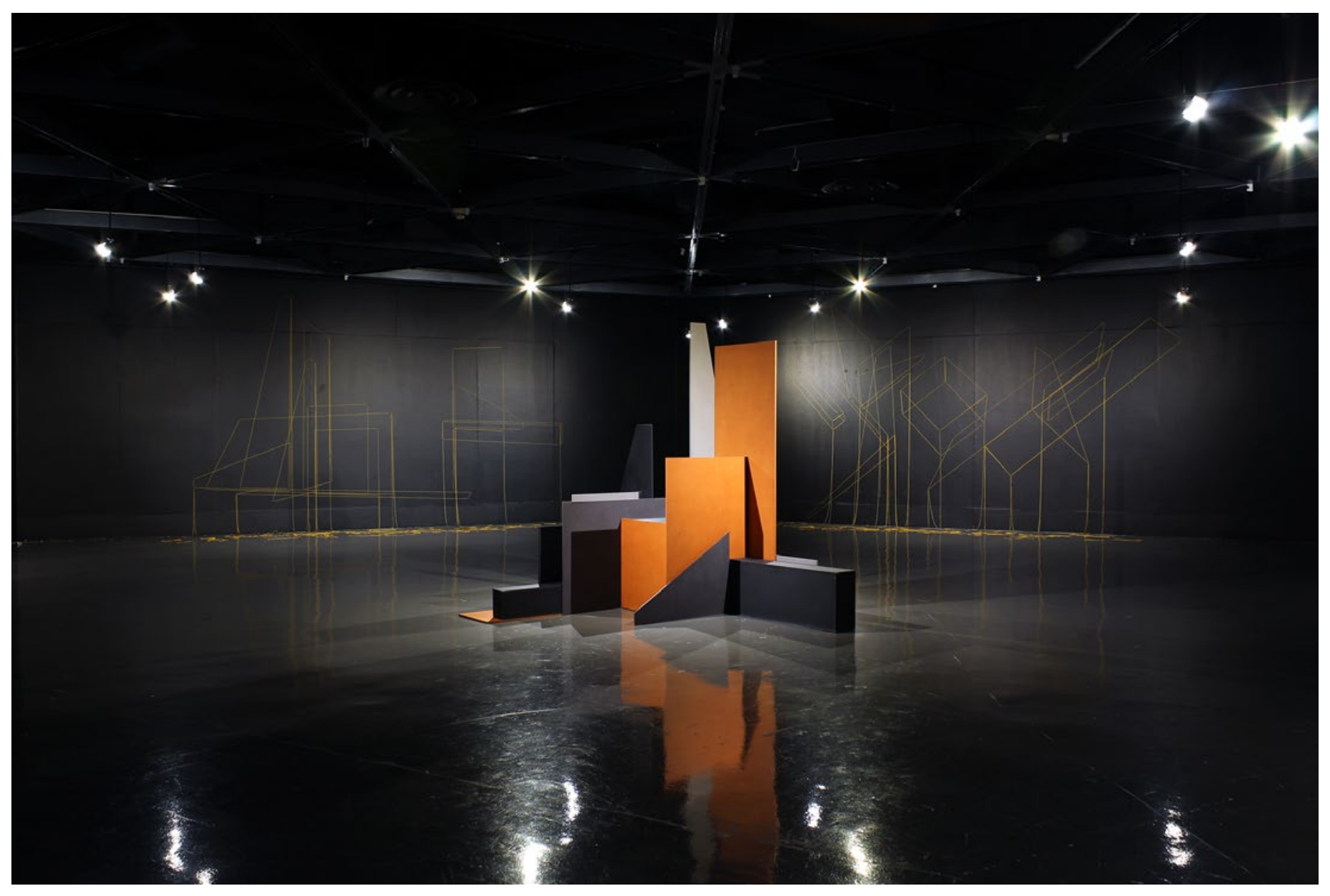




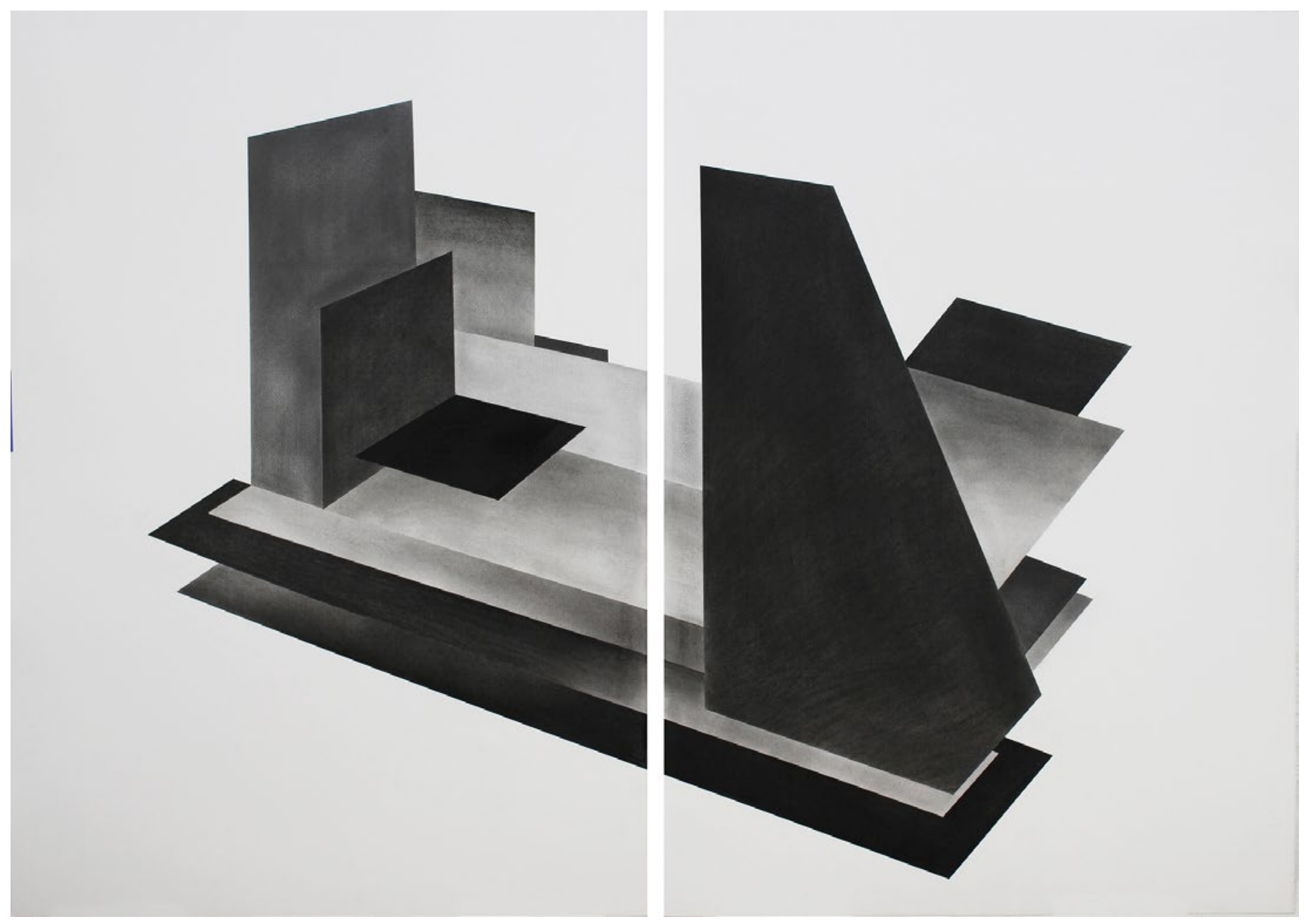




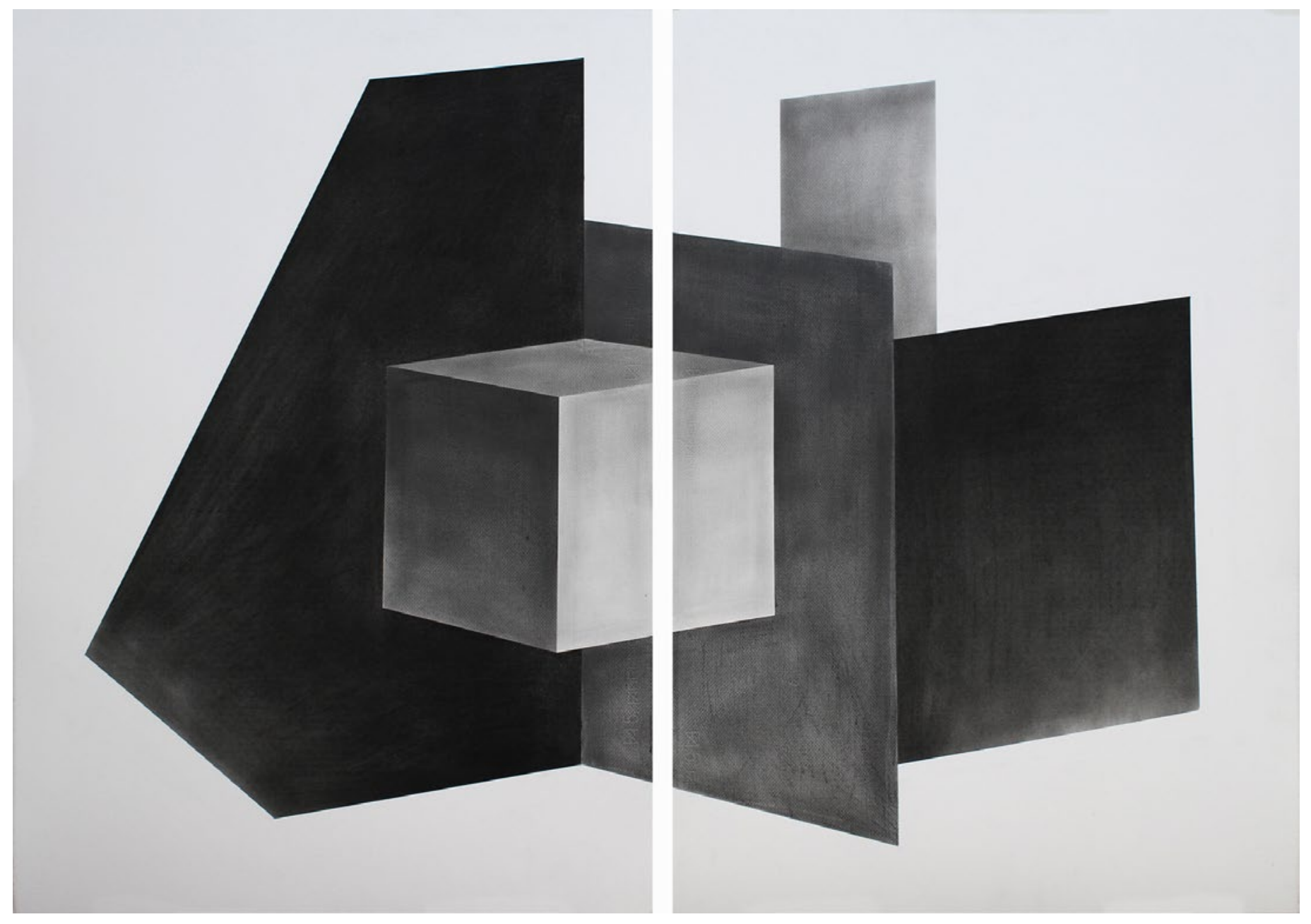


QUIRARTE + ORNELAS

Anabel Quirarte y Jorge Ornelas (Ciudad de México 1980/1979). Viven y trabajan en la Ciudad de México. Estudiaron la licenciatura en Artes Plásticas en la Escuela Nacional de Pintura, Escultura y Grabado (ENPEG) "La Esmeralda", México; y en la Academia de Artes Plásticas de Karlsruhe, Alemania. Su obra, realizada en colaboración desde 2004, ha sido expuesta individualmente en Nueva York, Frankfurt, Seúl, Monterrey, Ciudad de México, entre otras, y colectivamente en distintas ciudades de América, Europa y Asia. Dentro de los apoyos y reconocimientos que han obtenido se encuentran: beca de intercambio Baden-Württemberg en la Staatliche Akademie der Bildenden Künste Karlsruhe, Alemania; Premio Bienal Arte Lumen Tercera Edición, categoría Carrera media; Mención Honorífica en la XIII Bienal de Pintura Rufino Tamayo 2006; el apoyo Jóvenes Creadores otorgado por el FONCA.

Jorge Ornelas pertenece al Sistema Nacional de Creadores de Arte, desde 2019 a la fecha. 